\title{
From Play to Creative Extrapolation: Fostering Emergent Computational Thinking in the Makerspace
}

\author{
Rachel Horst \\ The University of British Columbia \\ Kedrick James \\ The University of British Columbia
}

Yuya Takeda

The University of British Columbia

\author{
William Rowluck \\ The University of British Columbia
}

Computational thinking (CT) has been hailed as a necessary competency that should be incorporated across the curriculum; however, research shows that CT is generally confined within programming curriculums. If we are to foster CT in areas like the humanities, we must extend our understanding of CT to include emergent and creative expressions of computational concepts. We explore the makerspace as a fertile environment for experimentation and play with CT concepts, which can then be extended through creative writing and imaginative extrapolation, during which learners metabolize and imaginatively project computational thinking beyond the confines of the actual and into rich potentiality.

Keywords: computational thinking, makerspace, creative writing, arts-based inquiry, new materialism

\section{CIRCUIT AS ALGO-RHYTHM}

The classroom is transformed into a clamorous workshop: orange wires spill from fish-tackle boxes accordioned open upon the table and offering an assortment of littleBit ${ }^{\mathrm{TM}}$ modules. Hands dart in and out of the boxes as makers intuitively discover the functions of each magnetic bit. The bits are colour-coded according to type: power, input, wire, output. Their soldered circuitry is tangible as braille upon the back of each module. Bits snap together magnetically, ensuring correct input-output orientation: A light turns on, nothing happens, a speaker emits a buzz causing eruptions of laughter. Very little explanation has been given other than that, together, the bits create circuits through which flows a signal. The signal may encounter a variety of possible modulations as it moves towards its output: motion, light, sound, or nothing - which becomes a problem to solve. Around the tables, makers collaborate, experiment, laugh, talk, and tinker towards an understanding of the bits and their functions. As discoveries are made, new problems arise: How can we make this sound more rhythmic? How can we cause the lights to blink in 
alternation? What kind of bit would we need to make the artifact fly? As makers become attuned with the technology, the making becomes more creative. Now a huddle of makers surrounds a maker-turnedmusician who has created an algorithmic synthesizer. The maker/musician collaborates with the technology/instrument as together they co-cause sounds to emerge from the speakers. Using a wire to split the signal, she has created parallel oscillations, one path of the signal loops on a sequencer, the other changes pitch at the touch of a keyboard bit. In between the sonic bits, LED lights blink on and off, alternating in time to the looping rhythm. Heads and feet of fellow makers embody the circuit-rhythm, moving in time to the output of beeps and tonal fuzz. The musician/maker tinkers with the algorithmic parameters of tone, speed, frequency. Smiles and laughter of collaborator/listeners are a direct feedback/output, causing the musician/maker to alter and refine the signal. Now the signal cuts into silence.

"We dropped the beat," a voice says.

A quick flurry of fingers along the circuit/algorithm, as the maker seeks the location of the glitch. Connections are tested, an oscillator is replaced, the circuit is restored, and the musical output resumes causing applause and laughter.

\section{COMPUTATIONAL THINKING ACROSS THE CURRICULUM}

Computational thinking (CT) has been widely identified and delineated as a necessary $21^{\text {st }}$ century competency that should be incorporated across the curriculum. In her influential 2006 paper, Wing writes: "To reading, writing, and arithmetic, we should add computational thinking to every child's analytical ability" (p. 33). Here Wing addends CT to a short list of basic academic skills- a list positioned as a conclusive set of discrete competencies. But these traditional or classical literacies have been problematized by scholars like the New London Group who decades ago called "for a much broader view of literacy than portrayed by traditional language-based approaches" (New London Group, 1996). While there seems to be consensus among CT promoters on the importance of developing fluid computational thinking across the curriculum (i.e. de Paula, Burn, Noss, \& Valente, 2017; Deschryver \& Yadav, 2015; Hsu, Chang, \& Hung, 2018), the bulk of the research continues to situate CT within the narrow confines of coding and programming, which, as Hsu, Chang, and Hung (2018) explain, is often understood to be "the easiest and most appropriate ways to teach CT." In their review of the CT literature, Hsu, Chang, and Hung go on to argue that, "such stereotypical ideas could confine the potential of logical thinking to a small percentage of subjects and learners" (p. 299). In the same way that we have broadened our understanding of 'traditional literacies' to "account for the burgeoning variety of text forms associated with information and multimedia technologies" (NLG, 1996, p. 61), so too, we must broaden our understanding of thinking computationally.

In this paper we argue that not only does a narrow understanding of CT and the adherence to strict definitions of its various techniques of thinking, confine the potential number of students who will gain access to CT learning opportunities and computationally enriched "literacy-as-events" (Merchant and Burnett, 2018), but it also confines our very understanding of computational thinking as a potential modality for creative inquiry and expression across the curriculum. Computational thinking can and should be integrated into the dynamic and generative assemblage that is the landscape of contemporary literacies. As DeSchryver and Yadav (2015) argue, "technological progress has brought about calls for the integration of new literacies and computational thinking to prepare students as problem solvers and critical thinkers. However, in teaching and learning, all three perspectives [creativity, computational thinking and new literacies] most often manifest in isolation" (p. 411). In this paper we explore how the makerspace can be a fertile environment for this called-for integration if we facilitate emergent, improvisational, and embodied computational thinking through play and creative experimentation with technology as illustrated in the above vignette. We explore how this learning and discovery can then be deepened and extended through creative writing. Our analysis of the creative outputs of the most recent 
iteration of our makerspace workshop reveals creatively interpreted computational thinking concepts suggesting a meaningful pathway forward for the integration of CT across the curriculum, but significantly in the humanities where it has been found to be most lacking.

First, we will explore the theoretical assemblage guiding our facilitation of an iterative series of makerspaces undertaken over three years (2016-2019) of exploratory study in the Digital Literacy Centre (DLC) of the University of British Columbia (UBC). We approach the makerspace through Merchant and Burnett's (2018) "literacy-as-event," which sees "literacy as an ongoing reassembling of the human and more-than-human" (p. 1). Second, we explore computational thinking in the context of scholarship on creativity and improvisation (Sawyer, 2006; Sawyer, 2011; Mishra \& Henriksen, 2017; Mishra, Koehler, \& Henriksen, 2011; Mishra \& Yadav, 2013)and the makerspace and littleBits ${ }^{\mathrm{TM}}$, which is a tangible user interface for designing purposive electronic objects and has been identified as a technological toy that can promote computational thinking concepts (Lin \& Shaer, 2016; Lin, 2015;Bdeir \& Ullrich, 2011). Finally, we take a look at arts-based computational thinking as revealed through creative writing, in the form of metaphor, narrative, and poetry.

We utilize a new materialist theoretical lens to identify collaborations between the maker and the made, the technology and the thinking, as well as the very nature of computational concepts employed by the human mind. We suggest there is room for and reason to widen the scope of what we accept as computational thinking and learning. In doing so, we avoid a narrowly defined and technocentric view of computational thinking as solely reading and writing computer code. If we allow for the creative and metaphoric application of computational thinking, we deepen our understanding of CT concepts, while simultaneously increasing our creative agency across the curriculum and opening up new pathways for unexpected and intra-agential collaborations.

\section{METHODOLOGY AS ITERATIVE SEQUENCING}

This paper is the synthesis of an ongoing initiative of the DLC called Digital DIY, in which we seek to enhance interest and engagement with digital and computational learning and literacies among teacher candidates in the Bachelor of Education Program, and as outreach to marginalized communities who have limited access to and hence confidence with new technologies. We actively promote an arts-based approach to digital research that prioritizes creative inquiry with new technologies as a means of facilitating learning. For three years we have facilitated makerspaces utilizing littleBits technology to encourage computational thinking in four different learning environments: the UBC Teacher Education Program (Vancouver), the West Kootenay Teacher Education Program (a UBC-run rural teacher education initiative located in Nelson, BC), the UBC Learning Exchange (an adult education centre located in Vancouver's Downtown Eastside, commonly referred to as the poorest postal code in North America), in an alternative school setting for at-risk youth (also located in the Downtown Eastside), and at the DLC lab.

This project was aided by the Haagenson Fund, which supported the purchase of the workshop kit of littleBits, as well as ten musical synth kits to augment the collection. The decision to include Korgaffiliated musical littleBits was strategic insofar as sound provides instant auditory feedback on manipulations of a circuit. Acoustic exploration, as we illustrate in the above vignette, creates an accessible path to computational thinking: 1) providing an analogical connection between an audio signal's path and digital signal processing, and 2) small adjustments of processors give an audible change to the output, and this instant feedback during haptic play leads to comprehension of the effect parameters for a given processor. Because of the appeal of creating electronic soundscapes, these musical kits inspirited some of the highest levels of engagement that we have witnessed, regardless of the location or participant demographics of our workshops. Participants have spanned a wide age range, from elementary students to seniors, and have included members of indigenous, immigrant, racialized and economically marginalized communities, in addition to mainstream university students and teacher educators in both rural and urban settings. Our intent was to see if this form of play-making would be equally effective in promoting computational thinking and digital literacy across these populations and locations. 
Before we could host workshops, we adopted the role of makers and learned the use and function of the bits so that we could assist future learners. Our first workshop, therefore, was held among members of the Digital Literacy Centre, and drawing on a key feature of computational thinking we gave direction to our learning in the form of a problem-solving challenge. Our goal was to create something that could be used to communicate an encoded message. The more we played with the toys ourselves, the more we were able to think problems through and design what we wanted to build before we started making it. To facilitate this conceptual planning stage, we took the symbols related to each bit and imported them as a library into an open source software called draw.io. An added benefit of this software tool is that it made it possible to not only design objects without the bits in hand, but it also provided a means for collaborative development and assessment of learning which could be implemented in a variety of educational settings.

In order to augment this abstract conceptual design, we developed a set of playing cards with the littleBit symbols, colour-coded by the four basic functions of the modules, and then invented some card games with rules for trading cards among players. We experimented in workshop settings by having different participants start with the playing cards, or the bits, or the draw.io software, then move on to the next station. We experimented with giving prompts such as problems to solve, or encouraging participants to develop their own object creations through unstructured play. Typically, however, unstructured haptic play with the littleBits modules provided the highest levels of initial engagement, and only after sustained investigation and increased familiarity with the technology was it possible for participants to design objects abstractly. Over the course of repeated workshops, we transitioned from a focus on conceptual design to tinkering and intuitive play, and from structured individual problem solving to more collaborative, arts-based and performative learning. In one key makerspace with teacher candidates in Vancouver, we created musical instruments and then experimented with graphical scoring of the output/feedback of those instruments. The workshop culminated in a musical performance, which was a purposive and public outcome of our learning.

In the course of our research, we have collected several hours of video footage from the makerspaces and have synthesized our observations, discussions and analysis of the footage into the above narrative vignette, which attempts to capture the complexity and interagentiality of the makerspace literacy-asevent and its rich possibilities for emergent and embodied CT. Forming the basis of our analysis below, we focus upon our most recent makerspace iteration which explored the potential of creative writing as an opportunity to metabolize the making and the made through narrative reflection, metaphor, and poetic expression. This creative writing extension has significant ramifications for reflective computational thinking generally, but specifically in terms of its integration into arts and humanities curricula.

\section{AN ASSEMBLAGE OF FRAMEWORKS}

Post humanist thinking extends our understanding of what materials matter in the construction of meaning-making in the makerspace. This perspective "orient[s] to literacy as an affective encounter generated through an ongoing reassembling of the human and the more-than-human" (Burnett \& Merchant, 2018, p. 2). As Wohlwend (2017) suggests, "Barad's agential realism seems promising for unpacking the sensory and the emergent produced in the materiality, fluidity and messiness of entangled bodies and things in a makerspace" (Wohlwend, 2017, p. 444). We further suggest that agential realism might provide a useful analytic tool for identifying emergent computational thinking in the intra-actions between human and non-human agents in the makerspace. "The usual notion of interaction assumes that there are individual independently existing entities or agents that preexist their acting upon one another,"

Barad explains in a 2012 interview. "According to my agential realist ontology ... 'individuals' [in addition to the observed phenomena of computational thinking] do not preexist as such but rather materialize in intra-action" (Kleinman, 2012). Utilizing Brennan \& Resnick's 2012 framework for assessing computational thinking processes, we take this agential realist approach to the "bodies and things in unfolding relation within the emergent flows" (Wohlwend, 2017, p. 447) of learning and playing with the makerspace technology, littleBits. In this way, we hope to illuminate emergent and creative 
computational thinking opportunities that can complement and complexify the more traditional approaches to identifying and promoting CT.

In line with this new materialist approach, we have taken up Merchant and Burnett's (2018) reframing of the New London Group's literacy event, to incorporate a more relational, inter-agential ontology, in which we attend to both the human as well as the more-than-human, the actual as well as the potential. Literacy-as-event has three central tenets: "(1) event is generated as people and things come into relation; (2) what happens always exceeds what can be conceived and perceived; and (3) implicit in the event are multiple potentialities, including multiple possibilities for what might materialize as well as what does not" (p. 5). Foundational to our making approach is the possibility inherent in the technology itself, as well as the collaborative space of the making environment. Literacy-as-event encourages us to be attuned to the rich potentiality for CT to emerge when things and people come into relation within the makerspace environment.

\section{DEFINING COMPUTATIONAL THINKING}

Computational thinking has been identified as an intellectual revolution, impacting research across the disciplines, and changing the very way we think (Bundy, 2007, p. 1). But what does it mean to think computationally? There have been many attempts at defining and delineating computational thinking, which was re-popularized by Jeanette Wing's 2006 influential paper, but has been around, under different guises, since as far back as the 1940s, according to Denning (2017), who cites George Polya's 1945, How to Solve It, a book exploring the "mental disciplines and methods that enabled the solution of mathematics problems," as a precursor to computational thinking. The concept of the algorithm, which is essentially a set of "unambiguous specifications for performing calculation, data processing, automated reasoning, and other tasks" ("Algorithm," n.d.), goes back to the $9^{\text {th }}$ century Persian astronomer, scientist, and mathematician, Abdullah Muhammad bin Musa al-Khwarizmi "often cited as "the father of Algebra" (Virtual exhibitions in informatics, n.d.). Concepts like 'coding' have ancient roots in manuscripts such as the Dresden codex, which dates back to the $13^{\text {th }}$ or $14^{\text {th }}$ century, and contains the itemized and organized data of the indigenous people of Mexico's Yucatan Peninsula: ritual schedules and procedures, important dates, traditions, and calculations for astrological and astronomical charts. A quick scan of computational thinking terminology (parallel, loop, sequence, algorithm) reveals the meaningful borrowing of concepts from other modes and techniques of thinking and inquiry.

Peter Denning (2017) takes a critical view of the current craze for CT and how it is widely presented as a modality of thinking that can benefit all learners across all curricula. These claims, he rightly observes, are unsubstantiated by the research, which it has been noted widely, has a dearth of studies looking at CT in the arts and humanities (de Paula, Burn, Noss, \& Valente, 2017; Deschryver \& Yadav, 2015; Hsu, Chang, \& Hung, 2018). To confuse the matter further, there are wide and various CT frameworks and definitions that, as Denning and Tedre (2016) write, "do not agree on what exactly should be taught about CT, how to assess whether students have learned CT, and who are the main beneficiaries of CT" (p. 120). Depending upon which framework one espouses, the answers to these questions will necessarily change.

In their review of "the state of the field" of computational thinking, Grover and Pea (2013) state that computational thinking is "in essence, thinking like a computer scientist when confronted with a problem" (Grover \& Pea, 2013, p. 39). This as a working definition is obviously problematic - computer scientists are not a unified group who think in one coherent and singular way. In fact, innovation and creativity emerge in those liminal spaces where people are thinking "outside of the box" of their field or discipline. DiSessa (2001), five years before Wing's influential paper, defined CT as consisting of three distinct categories: the material, the social, and the cognitive. "If material literacy is how and social literacy is where and for whom, cognitive literacy primarily describes why" (Berland, p. 197). Denning, on the other hand, prefers a narrower definition of CT which focuses on "computational steps and algorithms" in the formulation of problems and solutions (Aho, 2011). Whichever model or framework 
one chooses, it becomes helpful to tease apart and articulate specific computational concepts or thinking techniques, so that we know what we are looking for and how best to promote it.

Brennan \& Resnick's 2012 framework strikes us as particularly useful in promoting a nuanced understanding of CT. Theirs is both descriptively granular and broad enough to encompass a wider context for these concepts. The framework moves from discrete techniques like sequences, loops, and conditionals, then expands to include thinking practices such as reusing and remixing, and finally extends to broader transdisciplinary perspectives such as questioning and expressing. It is our assertion that if we are too narrow in our definition of CT, we lose the ability to identify and promote diverse manifestations of this thinking. We also inhibit creativity - which often occurs in the edges and in-between spaces of orderly thinking. Brennan and Resnick's framework allows for CT to be identified in multiple levels of engagement and practice: from the hands on, to the more contemplative and metaphorical; from intentional problem solving to experimental tinkering and problem-finding; from prescribed learning outcomes to more creative, improvisational, and aesthetic practice.

Ways of thinking are not discrete, separate, and coherent unto themselves, but overlap and commingle in assemblages of thought processes, embodied experience, and creative intuition. Many characteristics of computational thinking are meaningful to other ways of thinking. Remixing and reusing, for example, is a technique employed widely in creative inquiry. Sequences and loops can be found in both computer code as well as musical compositions. Questioning and expressing are necessary perspectives in all meaningful inquiry. It is useful to conceptualize computational thinking as one piece of this rich assemblance, and to be attentive to the overlaps and comminglings of thought processes and creative activity.

\section{CREATIVITY, TINKERING, AND PLAY}

Even more difficult perhaps, than carving out the parameters of computational thinking, is the task of defining creativity; yet there is an explicit demand for fostering creative thinking across the disciplines. Many assert that as technologies become increasingly advanced, humans will need to capitalize upon the things we do best - like think creatively (i.e. Powers, 2018). Creativity is at the heart of any innovation, technological or otherwise; it can also allow one to stay supple and engaged within the constantly changing landscape of new literacies. As DeSchryver and Yadav (2015) points out "new literacies are not just something that are 'new today,' but 'new every day of our lives,' their mastery and facilitation ... requires a great deal of creative thinking" (p. 415). According to Mishra and his colleagues at the Deep Play institute (Mishra \& Henriksen, 2017; Mishra \& Yadav, 2013), computational thinking and creativity can be seen to have many overlapping characteristics. Mishra, Koehler, and Henriksen (2011) highlight seven transdisciplinary creative cognitive tools: "perceiving, patterning, abstracting, embodied thinking, modeling, play, and synthesizing" (p. 24). These tools have obvious resonations with computational thinking as outlined in Brennan and Resnick's (2012) framework, for example: abstraction, patterns, and synthesis. Synthesis in a creative context, is the ability to bring together multiple sources, modalities, or ways-of-knowing into one project or process. Likewise, in computational thinking, synthesis is the ability to bring together multiple discrete units into one working model. Becoming aware of the similarities and resonations between $\mathrm{CT}$ and other ways of thinking, educators can begin to promote and facilitate CT in more diverse educational contexts and practices.

In our most recent iteration of the makerspace workshop, we encouraged learning through collaborative and improvisational tinkering and creative play over a teacher-led approach. Tinkering allows for problems to arise naturally within the logic space of the play. Rather than set out with a predetermined learning outcome, intuitive tinkering and play allows makers to discover problems within and through the making. "[M]any significant creative advances result from problem finding, when the problem is not known in advance, but emerges from the process of the work itself" (Sawyer, 2006, p. 6). Participant/collaborators were encouraged not to focus solely upon the artifact, but rather to explore the limits and extensions of the electronic/algorithmic circuit and to play with how it might be modified both physically in the dynamic and collaborative moment, but also metaphorically and creatively through narrative and poetic possibility. 


\section{THE MAKERSPACE AND MANIFEST COMPUTATIONAL THINKING CONCEPTS}

While human beings have been thinking in computational terms since we began codifying knowledge systems, Seymour Papert was perhaps the first to articulate computational thinking as a distinct approach to problem solving in his 1980 Mindstorms. It is no coincidence then, that Papert is also considered the

grandfather of the makerspace movement. Founded upon Papert's constructionist learning philosophy, makerspaces promote exploration with technologies that are specifically designed to be accessible and intuitive to use (Halverson \& Sheridan, 2014) and, as such, are fertile environments for the development of computational thinking (Berland, 2016). "Computationally rich environments and effective CT tools for school children must have low threshold and high ceiling, scaffold, enable transfer, support equity, and be systematic and sustainable" (Grover \& Pea, 2013, p. 40) Makerspaces provide this low threshold, with immediately accessible technologies that have no restrictions on exponentially increased complexity and application. As explained above, we take an unstructured and intuitive approach to the makerspace, aligned with a constructionist pedagogy that encourages students to discover through doing.

The technology at the heart of this intuitive play is littleBits; which allow learners to literally grasp complex concepts in their hands, haptically manipulating the components of circuitry without prior training in electronics. In her dissertation on technological toys and the promotion of computational thinking, Lin (2015) writes, "[i]n addition to supporting all of the computational practices and perspectives outlined by Brennan and Resnick [our chosen CT framework], littleBits also help users understand sequences, parallelism, and events, key concepts of computational thinking" (p. 19). LittleBits modules are the materialization of computational concepts: the circuit is essentially a physical algorithm and learners can interact with and manipulate the signal/code to produce different feedback/outputs. Like an algorithm, the circuit may contain parallels, loops, events; it can be remixed or elaborated, tested and debugged -- all the granular computational thinking concepts are manifest in this tangible user interface.

The makers and the technology, within the dynamic makerspace, co-create and facilitate outputs, which become immediate and generative feedback, "a hallmark of good learning environment design" (Berland, p. 199). In this collaborative environment, feedback comes in many forms, both the material feedback of the artifacts (whether and how the circuit works to produce light, sound, movement, etc.) as well as the

voluminous social feedback in terms of what the other people in the makerspace found valuable (or not)... sociomaterial feedback about tools [that are used] correctly or incorrectly; sociocognitive feedback about how they would build something differently...; and cognitive material feedback from watching other peoples' problems wrestling with and helping $\ldots$ build [the] artifact (Berland, 2016, p. 199).

Unlike structured learning activities which teach discrete CT skills through programming (the majority of studies focus on these kinds of pedagogical practices), we take a student-led constructionist view of learning-through-doing to provide opportunities for computational thinking to emerge in the intra-actions between human and non-human agencies in the makerspace.

\section{MOVING AWAY FROM THE TECHNOCENTRISM OF THE MAKERSPACE}

Seymour Papert noticed a tendency in computer education to make technology the focus of the learning rather than the medium of that learning. Brennan (2015), one of the scholars behind our chosen CT framework, and an advocate of Papert's constructionist approach to learning with technology, explains that technocentrism occurs when, "[t]he 'learning' is focused on learning about the tool/technology or the effects of the tool/technology itself, rather than learning with or through the technology. The questions that are asked about impacts and outcomes strive to isolate the technology as a source of change. We still seem hopelessly stuck in a technocentric view" (p. 289). The makerspace, for all its democratic and egalitarian ethos and philosophy, still has a tendency to make the technology 
central. There is a giddy rush, in the maker movement, to innovate and create and build with technologies, but there lacks an accompanying reflection about the implications of that building and making and an important critique of global capitalist manufacturing cycles and the impact artifacts have upon human lives and the environment. "While the shift might be from the corporate to the individual," Chachra (2015) writes in the Atlantic, "[the makerspace] mostly re-inscribes familiar values, in slightly different form: that artifacts are important, and people are not" (para. 7).

In our most recent makerspace workshop, we attempted to mediate the technocentrism of the makerspace by widening the scope of our attention and activity. We prompted the metaphorical and narrative imagination to explore the significance of technological fabrication for humanity, the future, and our complicated co-existence and co-becoming with the delicate and damaged more-than-human world around us.

The first hour of the workshop involved unstructured tinkering and play with littleBits in line with the methodologies described above. We then settled into a quiet and contemplative phase, during which we explored the ramifications of the technological artifacts and the act of making through writing. In line with the literacy-as-event, we used creative writing to attend specifically to the multiple potentialities of the making. We wanted to prompt a creative exploration of the rich possibilities inherent in the makerspace and how "people and things come into relation" (Burnett \& Merchant, 2018, p.5). Brennan (2015) highlights the importance of reflection in any meaningful constructionist learning experience. We take up this reflective piece and offer it as a creative extension of the making. In adding this layer of speculative creativity, we found that computational thinking processes emerged in the texts and imagining that exhibited a deepening and complexifying of the computational making and learning experience, and provided exciting possibilities for future extensions of computational thinking across the curriculum as we will discuss below.

\section{METABOLIZED ALGORITHMS: THREE CREATIVE OUTPUTS REVEALING COMPUTATIONAL THINKING}

The following excerpts are presented to reveal creative computational thinking as it emerges reflectively in narrative, lived experience, and aesthetic expression. Just as we did not set up the makerspace with a formal and specified problem to solve, rather we encouraged makers to intuitively, collaboratively, and creatively negotiate the bits and each other towards emergent and 'becoming' computational thinking and technological fabrication, so too we refrained from engaging in a prescriptive process for this writing extension to the making. The one constraint we gave ourselves was to orient the imagining forwards, into the future and future potentiality, making explicit "the multiple potentialities" of our literacy-as-event, including the "multiple possibilities for what might materialize as well as what [did] not" (Merchant \& Burnett, 2018, p.5). This writing was intended to provide an opportunity to imaginatively metabolize the computational thinking and learning, which "may never have been consciously apparent before..." the act of writing (Burnett \& Merchant, 2018, p. 7).

Using an intra-agential, post-humanist lens, we analyze and interpret the creative extensions looking for emergent expressions of computational thinking and knowing. In Tables 1.1, 1.2, and 1.3, we show a breakdown of each creative output according to Brennan and Renick's 2012 framework. We have flipped the framework, beginning with the more generalized perspectives and moving towards the discrete and descriptive techniques of CT. This choice grows out of our argument that the makerspace environment is aligned with the CT perspectives and practices, and that it can allow for the more granular CT concepts and techniques to emerge intuitively through the hands-on play, experimentation, and creative reflection. We suggest that beginning with a widened scope can encourage us to recognize and therefore foster CT thinking in the unexpected or liminal spaces between other curriculums, disciplines, and ways of thinking. In the same way that stargazers sometimes need to widen their perspective and look away from the intended focal point, in order to visually locate a star in the night sky, so too here, we suggest that widening the lens of our attention can allow CT to become apparent in unexpected places. 
We maintain, along with Barad (2007), that "[m]eaning is not a property of individual words or groups of words but an ongoing performance of the world in its differential dance of intelligibility and unintelligibility" (p. 149). The computational thinking here becomes intelligible both within the creative expressions themselves and how they are entangled with our analysis. If our theoretical frameworks can be thought of as the apparatus by which we define, measure, and gauge computational thinking, we are aware also that apparatuses "are not passive observing instruments; on the contrary, they are productive of (and part of) phenomena" (Barad, 2007, p. 142). In fact, we further suggest that a poem, narrative, or metaphor, can be a kind of apparatus with which to measure and know the world computationally.

\section{Algorithm as Origin Story- Billy Rowluck}

During the active portion of the makerspace event, Billy did not focus on building or designing an artifact, rather he was more interested in learning the names and functions of each bit. He situated himself in the emergent community of our makerspace, finding music on his Iphone that related to the improvisational and tangential discussions as they emerged and dissipated among us. At one point, he became interested in the artifact another maker was building. She had drawn a few figures on a piece of paper and placed the paper in a router so that the figures spun slowly around and around. Billy remarked that this artifact reminded him of the Korean Sangmo hat and how its ribbon spins during Pungmul dance performances. This led Kedrick to muse upon the mystical practice of the Whirling Dervishes, who whirl and spin for hours as a form of spiritual practice and worship. The material spinning of the router/artifact cascaded outwards into ideas of spinning and the spiritual symbolism of that spinning. Here we can see the thinking, making, and knowing in the makerspace as entirely entangled with the materiality of the technology, as well as the history and cultures of the makers in the room. "So that's the connection to the transcendent," Billy said, whose own indigenous heritage is at the forefront of his scholarship and experience in the world.

Billy took up the creative writing prompt and wrote an origin narrative, personifying the bits closely with the collaborator-participants in our makerspace and giving the bits voice and character. He imaginatively explored the function/agency of each bit and how they related and interacted with the others.

"I wanted to get everybody in here," he said. "That's part of what littleBits was doing for me, was connecting me." This focus on naming, origin, and function work towards a metaphor for human connection. His narrative reflects a spiritual understanding of the algorithm/circuit as a grand metaphorical schema, with each bit (or being) having a different purpose or function, but with the ultimate ability to fit together even in our differences.

- Hey temp sensor, how's it going?

- Good, but I'm getting a little hot.

- Yeah, and you're not so big, not like the synth speaker, keyboard, or Adam 's car.

- Yeah, hey, do you hear that?

- What?

- It sounds like the wind coming from Kyuyen's patch. Oh, what I wouldn't do to cool off! If I get too hot, things could shut down!

- Excuse me...

- Don't interrupt! 
- Sorry but...

- I said don't be rude... no one taught you any manners?

- Ijust wanted to say that I might be able to help you.

- You, help? You're not even a bit! I mean you don't even have colour and you think you could help?

- I know I'm not a bit, but I do something different.

- Okay, Mr. No-Colour-Bit, what do you do?

- I help bring wind, that is if you plug me in. Maybe I could help cool off temp sensor... hi.

- Hi, oh, what are you?

- I'm an output but I'm actually a bit too, but I don't look like bits like you.

- That's for sure. Well, why not?

(Clip shhhhooooooooshshsh)

- Ah, that feels good - o- my temp is going down. What kind of bit are you again? $\cdots$

- Okay, okay, I accept that you're a bit without colour. I think you're okay but why didn't we know about you before? I mean you fit so perfectly, it's almost like you were meant to be part of our patch. I guess you'll have to talk to Kyuyen, her patch has been working with me for, well, I think forever.

While this narrative does not reflect the more granular components of Brennan and Resnick's framework for computational thinking, it does reveal the foundational perspectives of expressing, connecting and questioning. Here the "[d]iscursive practice [of origin narrative] and material phenomena [of the patch as algorithm] do not stand in a relationship of externality to each other; rather, the material and the discursive are mutually implicated in the dynamics of intra-activity. The relationship between the material and the discursive is one of mutual entailment" (Barad, 2007, p. 152). The practice of creative imagining within the maker-space literacy-as-event, allowed for an explicit enactment of this entangled knowing through narrative. Writing in this way provides a rich and meaningful pathway forward for creating cultural connections with computational thinking and learning.

\section{Algorithm as Metaphor-Yuya Takeda}

"I think with this layout of this table, that I was aware of what other people were doing.... [W]e interacted directly with each other and collaborated a little bit... I was trying to be open for that input from the environment ... littleBits was also a kind of product of this invisible dialogue happening with other people and such. And that the implication I get from that experience is that ... there are certain kinds of patterns ... regularized patterns that we interact with things, but when we look closely, other people do things ... very differently and a good example is cooking. I live in a big house, and I constantly have new roommates. And every time new roommates come in and when I see others cooking their things, people do cooking very differently. Little by little, I'm incorporating those ways of cooking things and then my way of interacting with foods changed. So littleBits - if we break things into little bits, we 
see - the same thing being used for very different purposes. And kind of paying attention to those things you can change your practice."

Here Yuya implicates the collaborative space of making as an important feature of how creative potential is influenced and actualized in the social-constructionist, embodied experience of learning in the makerspace environment. This connects closely to the sense of literacy-as-event, wherein a participatory co-construction of situated meaning informs and reinforces his own literacy practices. The metaphor of the practice of cooking - the way people prepare, sequence and combine ingredients - reveals some of the more granular CT concepts at work, such as sequence and signal processing, parallelisms, conditionals, and loops. We see Yuya approach the parallel algorithms at work in the kitchen, each roommate caught up in their own cultural and historical patterns of preparing food. He maps the circuit onto these patterns, towards the insight that preparing food is not a fixed and immotile whole, rather these practices are modularized and can therefore be broken down and reassembled towards new opportunities for meaningmaking and experience. Learning in the participatory, collaborative, and inter-agential environment of the makerspace is parallel to the communal kitchen; through narrative reflection Yuya explores how we are entangled in material processes and that "[t]his field of possibilities is not static or singular but rather is a dynamic and contingent multiplicity" in which we can remix and reuse the metaphorical 'bits' of our rote practices, towards fresh insights and discovery (Barad, 2007, p. 147).

\section{Algorithm as Language - Kedrick James}

Kedrick took up the creative writing extrapolation of our maker-space learning and interpreted it through poetry. In his introduction to his poetic performance he explained that he was interested in the idea of language itself as a kind of signal processing, in which one "modulate[s] whatever signal to address whatever kinds of audiences and you have different outputs and different purposes or uses of language." His poetic process here, "reduced language ... to its electronic signature and allowed it to diversify." He took the inputs of the human and the more-than-human agencies in our environment and modulated the signal through poetic play. He explains that he was interested in exploring "that issue of many languages or the incoherency of even the same language between different disciplines."

\section{Problems of Working Through We-All-Knew New Technologies}

We planned a language of pulse orbits. It was our answer to Babel.

An everyone-knows-m-n-ohm-p anthem.

Pulse atomic structure as political square wave dancing

through the grapevine signals you sign. A blast radius zoology

the beeps and squawks of our wireless love-life

breeding bit-sign signal processing: somebody's language

knows a foreign tongue is licking electrical sweet wubwub in your ear lobe

contacting a spiritual glitch speak, a serious heavy pelting tandem diadem plantation

so volt straight up, yer satellite babysitter sequence in symphonic radiant sparklets

an onmicast simulation engine all together now, nobody is

better but bites brain candy the bitter twist should you wish it

can drift by flash to ion nimbus cozy cubbyhole bed, ridden by Aldebarren

the old sink down in dioramas of home spun dialectical osmosis,

oscillator shoulder pads like in the 2080 s - look so goofy now, cut to the

LED glint in X-ray eyeballs, the gall stone bust tone banquet,

the gamma ray surgery freaks to taste, flits and lifts olfactory enhancement

industrial regulation board bashing

the transom in arc-angel politics of guilty admission stick to

singing we all knew and spoke in unison compelling us to see through

rose coloured sleepless glasses... 
Here, Kedrick creatively synthesizes the material and ideational inputs of the entangled materialities in our maker-space environment. The poem is a kind of interface through which the signal of our learning and making travels and bifurcates and parallels, glitching upon wordplay and free association. The materiality of the bits themselves is present as language: the "beeps and squawks" of the Korg synth kit become one of many "foreign tongue[s]" in this "answer to Babel." There is a post-humanist stream of consciousness at work here, as he playfully merges the human and the technological with "satellite babysitters" and "x-ray eyeballs" and "gamma ray surgery freaks to taste." This creative extrapolation is a kind of algorithm as language, but the computational thinking is fractalized through poetic play and irreverence for the binaries and boundaries of bodies and definitions.

\section{AN INTEROPERABILITY OF COMPUTATIONAL THINKING CONCEPTS ACROSS CURRICULUMS AND MATERIALITIES}

While scholars since Papert (Brennan, 2015; Hickmott \& Prieto-Rodriguez, 2018) have noted the tensions between quantitative assessment of learning and a constructionist environment such as the makerspace, tuning our attention to noticing creative and emergent learning can mediate that tension. Allowing for and being attentive to emergent CT can provide educators with opportunities to nurture that emergence with further creative and enriched CT inquiries. As Berland (2012) writes, "[d]eveloping computational literacy is a complex prospect-[it] requires using diverse skills in multiple contexts across cognitive, social, and material dimensions" (p. 204). The makerspace provides one such generative context for a computationally enriched literacy-as-event. Through the important extension of creative writing, learners can connect to and express computational concepts, both deepening the learning and providing educators with evidence of that learning. This arts-based metaphorical and poetic extrapolation of the making can be a meaningful way of embedding computational thinking in the arts and humanities, where the research has shown it to be lacking. This intervention will require that educators become aware of their own important role in defining and identifying emergent computational meaning-making. CT concepts such as the algorithm, are not objective materialities; as Barad (2007) writes, "“concepts' ... and 'things' do not have determinate boundaries, properties, or meanings apart from their mutual intraactions" (p. 149) - educators therefore have a participatory role in the becoming of computational thinking in any literacy-as-event. A new materialist theoretical approach seems well-calibrated for a broader awareness of computational thinking as an assemblage of the human and the more-than-human in thought processing. By attending to the collaborations between the humans and the technologies within the makerspace environment, we can widen and deepen our ability to both identify and foster emergent computational thinking. This enriched understanding allows us to facilitate the interoperability of computational thinking across both curriculums and materialities.

\section{REFERENCES}

Aho, A. (2011, January). Ubiquity symposium: Computation and computational thinking. Ubiquity: Information everywhere. Retrieved from http://ubiquity. acm.org/article.cfm?id=1922682

Barad, K.M. (2007). Meeting the universe halfway: Quantum physics and the entanglement of matter and meaning. Durham: Duke University Press.

Bdeir, A., \& Ullrich, T. (2011). Electronics as material: LittleBits. Conference: Proceedings of the 5th International Conference on Tangible and Embedded Interaction (pp .371-374). Funchal, Madeira, Portugal. doi:10.1145/1517664.1517743

Berland, M. (2016). Making, tinkering, and computational literacy. In Y.B. Kafai, K. Peppler, \& E.R. Halverson, Makeology: Makers as learners (volume 2). London: Taylor and Francis.

Brennan, K. (2015). Beyond technocentrism: Supporting Constructionism in the Classroom. Constructivist Foundations, 10(3), 289-296. 
Brennan, K., \& Resnick, M. (2012). New frameworks for studying and assessing the development of computational thinking. Conference: Proceedings of the 2012 annual meeting of the American Educational Research Association. Vancouver, Canada.

Bundy, A. (2007). Computational thinking is pervasive. Journal of Scientific and Practical Computing, l(2), 67-69. Retrieved from

https://pdfs.semanticscholar.org/d3b5/562aa8399ecbdcc40b98108229aa54e12449.pdf

Burnett, C., \& Merchant, G. (2018). Literacy-as-event: Accounting for relationality in literacy research. Discourse: Studies in the Cultural Politics of Education, pp. 1-12.

The New London Group. (1996). A pedagogy of multiliteracies: Designing social futures. Harvard Educational Review, 66(1), 60-93. doi:10.17763/haer.66.1.17370n67v22j160u

de Paula, B., Burn, A., Noss, R., \& Valente, J.A. (2018). Playing Beowulf: Bridging computational thinking, arts and literature through game-making. International Journal of Child-Computer Interaction, 16, 39-46.

DeSchryver, M.D., \& Yadav, A. (2015). Creative and computational thinking in the context of new literacies: Working with teachers to scaffold complex technology-mediated approaches to teaching and learning. Journal of Technology and Teacher Education, 23(3), 411-431.

Halverson, E.R., \& Sheridan, K.M. (2014). The maker movement in education. Harvard Educational Review, 84(4), 495.

Hickmott, D., \& Prieto-Rodriguez, E. (2018). To assess or not to assess: Tensions negotiated in six years of teaching teachers about computational thinking. Informatics in Education, 17(2), 229-244.

Hsu, T., Chang, S., \& Hung, Y. (2018). How to learn and how to teach computational thinking: Suggestions based on a review of the literature. Computers \& Education, 126, 296-310.

Keune, A., \& Peppler, K. (2019). Materials-to-develop-with: The making of a makerspace. British Journal of Educational Technology, 50(1), 280-293.

Lin, V., \& Shaer, O. (2016). Beyond the lab: Using technology toys to engage South African youth in computational thinking. Conference: Proceedings of the 2016 CHI Conference Extended Abstracts on human factors in computing systems (pp. 655-661). San Jose, California, USA.

Lin, V.J. (2015). Computational thinking and technology toys. (Unpublished honours thesis). Wellesley College, Wellesly, USA.

Mishra, P., \& Henriksen, D. (2017; 2018). Creativity, technology and education: Exploring their convergence (1st 2018 ed.). New York: Springer. doi:10.1007/978-3-319-70275-9

Mishra, P., Koehler, M.J., \& Henriksen, D. (2011). The seven trans-disciplinary habits of mind: Extending the TPACK framework towards 21st century learning. Educational Technology, 51(2), 22.

Mishra, P., \& Yadav, A. (2013). Of art and algorithms: Rethinking technology \& creativity in the 21 st century. TechTrends, 57(3), 11.

Papert, S. (1980). Mindstorms: Children, computers, and powerful ideas. New York: Basic Books.

Papert, S. (1987). Information technology and education: Computer criticism vs. technocentric thinking. Educational Researcher, 16(1), 22-30. doi:10.3102/0013189X016001022

Powers, A. (2018, April 30). Creativity is the skill of the future. Forbes. Retrieved from https://www.forbes.com/sites/annapowers/2018/04/30/creativity-is-the-skill-of-thefuture/\#2c57d $88 \mathrm{f} 4 \mathrm{fd} 4$

Sawyer, R.K. (2006). Explaining creativity: The science of human innovation. Oxford University Press.

Sawyer, R.K. (2011). Structure and improvisation in creative teaching. Cambridge: New York: Cambridge University Press. doi:10.1017/CBO9780511997105

Virtual exhibitions in informatics, University of Klagenfurt. (n.d.). Retrieved from http://csexhibitions. uni-klu.ac.at/index.php?id=193

Wikipedia contributors. (2019, September 11). Algorithm. In Wikipedia, The Free Encyclopedia Retrieved September 13, 2019, from https://en.wikipedia.org/w/index.php?title=Algorithm\&oldid=915125900

Wing, J. (2007). Computational thinking. Carnegie Mellon University. Retrieved from https://www.cs.cmu.edu/afs/cs/usr/wing/www/ComputationalThinking.pdf 


\section{APPENDIX}

TABLE 1

ASSESSING EACH CREATIVE OUTPUT USING

BRENNAN \& RESNICK'S (2012) FRAMEWORK FOR COMPUTATIONAL THINKING

\begin{tabular}{|c|c|c|c|}
\hline & \multicolumn{3}{|c|}{ Perspectives } \\
\hline & expressing & connecting & questioning \\
\hline $\begin{array}{c}\text { Algorithm as origin } \\
\text { narrative }\end{array}$ & $\checkmark$ & $\checkmark$ & $\checkmark$ \\
\hline $\begin{array}{l}\text { Algorithmic as } \\
\text { metaphor }\end{array}$ & $\checkmark$ & $\checkmark$ & $\checkmark$ \\
\hline $\begin{array}{l}\text { Algorithmic as } \\
\text { poetry }\end{array}$ & $\checkmark$ & $\checkmark$ & $\checkmark$ \\
\hline
\end{tabular}

TABLE 2

\begin{tabular}{|c|c|c|c|c|}
\hline \multirow{2}{*}{} & \multicolumn{4}{|c|}{ Computational Thinking Practices } \\
\cline { 2 - 5 } & $\begin{array}{c}\text { Being incremental } \\
\text { and iterative }\end{array}$ & $\begin{array}{c}\text { Testing and } \\
\text { debugging }\end{array}$ & $\begin{array}{c}\text { Reusing and } \\
\text { remixing }\end{array}$ & $\begin{array}{c}\text { Abstracting and } \\
\text { modularizing }\end{array}$ \\
\hline $\begin{array}{c}\text { Algorithm as origin } \\
\text { narrative }\end{array}$ & $\mathrm{X}$ & $\mathrm{X}$ & $\checkmark$ & \\
\hline \multirow{2}{*}{$\begin{array}{c}\text { Algorithm as } \\
\text { metaphor }\end{array}$} & $\checkmark$ & $\checkmark$ & $\checkmark$ & $\checkmark$ \\
\hline \multirow{2}{*}{$\begin{array}{c}\text { Algorithm as poetry } \\
\text { nyyyy}\end{array}$} & $\checkmark$ & $\mathrm{X}$ & $\checkmark$ & \\
\hline
\end{tabular}


TABLE 3

\begin{tabular}{|c|c|c|c|c|c|c|c|}
\hline & \multicolumn{7}{|c|}{ Computational Thinking Concepts } \\
\hline & $\begin{array}{l}\text { sequence } \& \\
\text { signal } \\
\text { processing }\end{array}$ & loops & events & parallelisms & conditionals & operators & data \\
\hline $\begin{array}{c}\text { Algorithm as } \\
\text { origin } \\
\text { narrative }\end{array}$ & $\checkmark$ & $\mathrm{X}$ & $\checkmark$ & $\checkmark$ & $\mathrm{X}$ & $\mathrm{X}$ & $\mathrm{X}$ \\
\hline $\begin{array}{l}\text { Algorithm as } \\
\text { metaphor }\end{array}$ & $\checkmark$ & $\checkmark$ & $\checkmark$ & $\checkmark$ & $\checkmark$ & $\checkmark$ & $\mathrm{X}$ \\
\hline $\begin{array}{c}\text { Algorithm as } \\
\text { poetry }\end{array}$ & $\checkmark$ & $\checkmark$ & $\checkmark$ & $\checkmark$ & $\checkmark$ & $\mathrm{X}$ & $\mathrm{X}$ \\
\hline
\end{tabular}

